\title{
Analysis of Air Quality in Selected Areas of a Poultry Processing Plant with the Use of a Microbiological Air Sampler
}

Author(s)

\section{Konieczny PI}

Cegielska-Radziejewska R'

Mroczek E'

Dziedzic J'

Department Food Quality Management Poznań University of Life Sciences, Wojska Polskiego 71, PL-60-625 Poznań, Poland

\section{nail Address}

Corresponding author e-mail address Ewelina Mroczek

Department Food Quality Management, Poznań University of Life Sciences, Wojska Polskiego 71, PL-60-625 Poznań, Poland Phone: 603418171

Email: ewelina.mroczek@up.poznan.pl

\section{EKeywords}

Poultry processing plant, microbiological air quality, impaction technique.

\section{ABSTRACT}

The aim of the study was to analyze the air quality in selected production facilities specified as the so-called "high-risk zones". Air samples were analyzed using either the sedimentation or the impaction methods. The impaction method showed the applicability of the air sampler in in-situ measurements. An increase in the numbers of aerobic bacteria was observed in most air sample collection sites as the duration of the production time increased. At the three successive dates, it amounted to $163 \mathrm{cfu} / \mathrm{m}^{3}, 205 \mathrm{cfu} / \mathrm{m}^{3}$, and $324 \mathrm{cfu} / \mathrm{m}^{3}$, respectively. Such dependence was not observed by the of sedimentation method. It was stated that the impaction technique is better to precisely determine numbers of bacteria, yeast, and molds in the air of poultry processing areas. Analyses showed a high level of microbial air contamination in the examined production areas in relation to the guidelines applied in the assessment of indoor air contamination. Based on the recorded results, it was recommended to undertake immediate corrective actions, consisting in the replacement of filters in the refrigeration and air conditioning equipment, as well as to provide comprehensive training for the employees working in the selected facilities.

\section{INTRODUCTION}

Microbial contamination of air in production facilities is a major source of biological hazard in food production (Ellerbroek, 1997; Whyte et al., 2001). Air is a medium promoting microbial spread. In addition, air plays a significant role in the transmission of pathogens and may implicated in contamination of food at various stages of processing (Lues et al., 2007). Contamination of processed foods can occur due to poor water quality and unacceptable levels of airborne microorganisms in the processing environment (Syne et al., 2013). Microorganisms found in the form of bioaerosols may cause human health problems, such as allergies, and may impair the functions of the respiratory, immune and nervous systems. Additionally, the presence of foodborne pathogens in poultry meat and meat products can result also in economic losses to producers due to recalls from market places (Syne et al, 2013).

Bioaerosols contain yeast and bacterial cells, viruses, and fungal spores (Jain, 2000; Buchanan et al., 2000; EHEDG, 2006). Typical microflora in the air of production facilities in food industry plants includes bacteria of the genera Micrococcus, Staphylococcus, Moraxella and Bacillus, as well as molds of the genera Penicillium, Cladosporium, Alternaria and Fusarium (Ellerbroek, 1997; Kręgiel, 2006). Microorganisms found in the air most frequently originate from raw materials, production lines, ventilation systems and employees. The presence of fungi in the air of production areas is connected with their migration from the outdoor environment, as well as their presence in production facilities and on walls and ceilings (Jain, 2000; EHEDG, 2006). The susceptibility of raw 
materials and products to air microbial contamination varies and is dependent to a considerable degree on their nutritive value (Kręgiel, 2006). Appropriate ventilation, facilitating the removal of contaminated air, is a significant factor to reduce air contamination. Ventilation ducts may be sources of air microbial contamination when filters installed in those ducts are not effective. An inadequate ventilation system is the primary cause of high humidity, leading to the growth of filamentous fungi (Buchanan et al., 2000).

Microorganisms retain their virulence in the air, thus it is necessary to control air contamination in food production areas in order to facilitate detection and elimination of potential health hazards resulting from their presence (Kaiser \& Wolski, 2007; Srikanth et al., 2008). The application of the traditional sedimentation method to assess air quality in cases when it is impossible to determine accurately the volume of tested air does not always yield reliable results (Blachno, 2009). For this reason, novel, improved methods are being introduced to sample air and to evaluate microbial air contamination. These techniques include the so-called impaction method using various designs of air samplers (Kalwasińska et al., 2013). Such devices are successfully applied, e.g., for the assessment of the presence of microorganisms in air in livestock housing facilities, in sewage management facilities, in residential buildings, as well as for monitoring of air quality in archives and libraries (Burrel, 1991; Blachno, 2009).

The aim of this study was to assess applicability of a microbial air sampler for the analyses of air contamination in selected production facilities of a poultry processing plant.

\section{MATERIAL AND METHODS}

Microbiological analysis of air in a processing hall was conducted using the sedimentation and impaction methods simultaneously. In the case of the sedimentation method, an open Petri dish with a respective medium was exposed to air samples for $30 \mathrm{~min}$, closed and incubated. In the impaction method, air contamination was assessed using a MAS100 Eco air sampler by MERCK (Germany) (Collins et al., 1989; Kalwasińska et al., 2013). The principle of the operation of this device consists in sucking in a specified, pre-programmed volume of air directly onto Petri dishes with the medium located under a perforated plate. The air sampling rate is $100 \mathrm{~L} / \mathrm{min}$, making it possible to collect up to $1000 \mathrm{~L}$ of air within one series. After microbial determinations, the Petri dishes were incubated under the same conditions as the culture sedimentation plate technique.
The air sampler's lid, was first sterilized at $121^{\circ} \mathrm{C} / 15$ min and then sanitized with $70 \%$ alcohol, before and after each sampling. These measures meet the strict requirements of air control recommended for sterile and "clean" zones. Sample collection time should not exceed 10 minutes due to the risk of dehydration of the medium surface. The working area of the device used for air sampling is disinfected after each measurement (Collins et al., 1989).

The number of grown colonies was converted into colony forming units according to the formula (Ogórek \& Pląskowska, 2011): $X=(\alpha \times 1000) / N$ where: $\alpha$-the number of grown colonies, $V$ - volume of sampled air.

Microbiological analyses were performed in a total of 216 samples, 108 for each of the two above mentioned methods. The total number of aerobic bacteria was determined using CASO Agar with casein peptone from soy flour, while yeasts and molds were analyzed on selective media using Sabouraud Agar with addition of $4 \%$ dextrose. Samples were incubated for $72 \mathrm{~h}$ at $30^{\circ} \mathrm{C}$ for aerobic bacteria, and for five days at $25^{\circ} \mathrm{C}$ for yeasts and molds.

Samples were collected in selected locations of production facilities in a processing plant, where further-processed and packed products, such as frankfurters, poultry Kabanos-type sausage, and hamburgers, are produced. Due to the potential high risk of contamination of processed meats produced in the production floor by microorganisms, particularly high hygienic standards needs to be maintained, and therefore, this area is referred to as the high risk zone (Battersby, 2009; Evers \& Chardon, 2010). In the diagram of the evaluated poultry processing plant, such zone are highlighted and the air inlet points are indicated (Fig. 1).

The air sampling procedure and locations were discussed with HACCP team members and designed so that samples were collected accurately and consistently to reflect the concentrations of microorganisms at the place and time of sampling. Efforts were made to select locations that provide representative air samples during a normal operating period has been taken. In consequence, air was sampled in the following locations in the production area:

[1] bulk products cooler

[2] space over tunnel no. IV

[3] space inside tunnel no. IV

[4] space behind tunnel no. IV

[5] packing hall I

[6] space in front of tunnels nos. I and II. 


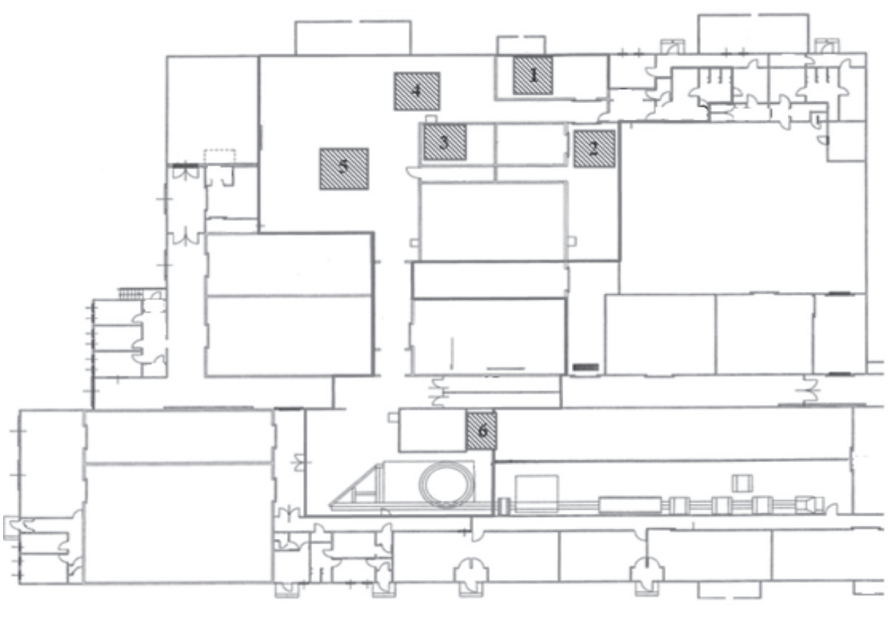

Figure 1 - A diagram of a poultry processing plant highlighting the "high-risk area" (red line), and the number indicate the locations where samples were taken.

Samples were collected on three different days and at different times in order to assess the quality of tested air in different technological situations, i.e.:

- date I - in the morning hours, i.e., 8:00 - 10:00 a.m. (the beginning of the production process, several employees involved, following night disinfection of facilities, on a day with a typical failure-free load of production),

- date II - in the noon hours, i.e., 12:00 - 3:00 p.m. (during the first shift, in the period of the highest intensity of production operations),

- date III - in the evening hours, i.e. 5:00 - 7:00 p.m. (towards the end of the last shift, on the day of intensive production of several types of processed meat products).

\section{RESULTS AND DISCUSSION}

Air sampling sites were selected after a site inspection and consultations with the chief process engineer, during which the tested sites were identified, i.e., the cooler (denoted as [1] in Fig. 1), the packing hall (denoted as [5] in Fig. 1) and freezing tunnels (denoted as [2-4] in Fig. 1). There are locations where air contamination results from the simultaneous action of several factors, such as temperature and humidity, the number and time of operation of devices that move air (air-conditioners, ventilators, fans), as well as the number and behavior of employees working at production lines.

Microbial air contamination varied and depended on the sampling site, the date of sample collection and the method applied to assess the level of contamination.

The results of the analyses concerning aerobic bacteria and yeasts and molds for the impaction method are presented in Table 1. In most air samples collected on date I, the total bacterial count was lower than that in samples collected on dates II and III. Bacterial air contamination in the production facilities increased with the duration of the production process. In most examined locations, the lowest bacterial count was recorded in the morning, following the disinfection of these facilities. Kang \& Frank (1989) recommended maximum levels of $180-360 \mathrm{cfu} / \mathrm{m}^{3}$ of air for mesophilic aerobic bacteria and $70-430 \mathrm{cfu} / \mathrm{m}^{3}$ for yeast and molds. According to Krzysztofik (1992), the admissible level of air contamination in meat industry in terms of the total bacterial count is $500 \mathrm{cfu} / \mathrm{m}^{3}$. Wiejak (2011) considers higher values as a general hygienic irregularity and an indication for further analyses. That author pointed to the fact that research centers apply various scales in the evaluation of microbial air contamination, but there is no legislation on this matter. Irrespective of the sampling site, the admissible level of contamination was not exceeded on any sample collection date in terms of total bacterial count when the compaction method was applied.

As shown in Table 1, the number of yeasts and molds determined using the impaction method markedly varied. In most measured sites, the lowest yeasts

Table 1 - Aerobic bacteria and yeast and mold counts obtained by the impaction method, according to sampling site.

\begin{tabular}{|c|c|c|c|c|c|c|}
\hline \multirow{3}{*}{ Type of room } & \multicolumn{6}{|c|}{ Impaction method } \\
\hline & \multicolumn{3}{|c|}{$\begin{array}{l}\text { Aerobic bacteria } \\
\quad\left(\mathrm{cfu} / \mathrm{m}^{3}\right)\end{array}$} & \multicolumn{3}{|c|}{$\begin{array}{l}\text { Yeasts and molds } \\
\left(\mathrm{cfu} / \mathrm{m}^{3}\right)\end{array}$} \\
\hline & Date I & Date II & Date III & Date I & Date II & Date III \\
\hline Bulk products cooler & 35 & 125 & 195 & 70 & 290 & 300 \\
\hline Outside tunnel IV & 150 & 190 & 460 & 215 & 425 & 245 \\
\hline Inside tunnel IV & 130 & 130 & 155 & 195 & 210 & 245 \\
\hline Exit of tunnel IV & 150 & 270 & 355 & 190 & 520 & 160 \\
\hline Packing hall I & 280 & 445 & 300 & 260 & 610 & 210 \\
\hline $\begin{array}{l}\text { Production floor, in front of } \\
\text { tunnels I and II }\end{array}$ & 230 & 70 & 480 & 165 & 255 & 125 \\
\hline
\end{tabular}

Explanatory note: for Dates I, II, III, average values of three replicates are given $(n=3)$ 
and molds counts were recorded on date I. The high yeast and mold count recorded on date II in sampling sites, such as the packing hall or the production floor, indicates that an increase in production intensity may have been a significant factor affecting the level of air contamination in these locations.

High throughput, associated with a high number of employees, high work intensity of the production lines, and operation of additional production equipment, all contribute to the deterioration of the microbial air quality of the production space. Krzysztofik (1992) proposed 50 $\mathrm{cfu} / \mathrm{m}^{3}$ as the maximum allowable value for mold and yeast counts in food-producing facilities. The results obtained in the analyzed plant indicates that the mean yeast and mold count determined using the impaction method markedly exceeded that level in all sampling sites.

Mean counts of investigated microbiological parameters, determined at the same locations, but using the sedimentation method, are presented in Table 2. When this method was applied, no such clear dependence of bacterial counts on production rate or production duration was detected. Air contamination, expressed in terms of bacterial counts above the level recommended by Krzysztofik (1992), was found in the cooler (storing bulk unpackaged products) on date I, in the freezing tunnels IV on dates I and III, and in the packing room on date I. Moreover, a marked variation in yeast and mold counts among dates and measurement sites was also observed when the sedimentation method was applied. In most cases, the allowable air contamination levels for this microbial group were greatly exceeded. Yeast and mold counts only met the requirements recommended in literature (Krzysztofik, 1992) in the room in front of tunnel IV on date I and the production floor in front of tunnel IV on date I, and in front of tunnel II on date III.
Considering all sampling dates, the highest yeast and mold counts were found in the air inside tunnel IV, i.e., where a large number of air-conditioners was located. Based on the results obtained by the sedimentation method, it was difficult to determine any dependences; on the other hand, it was established that yeast and mold counts were dependent to a considerable degree on air sample collection site.

When comparing results of analyses of air samples collected by the sedimentation and impaction methods, it needs to be stressed that the results provided by the two methods are frequently divergent. These differences can be ascribed both to the technique applied for air sampling and to factors of the sampling location, such as air movement. Such observations were also made by other authors, who indicated that the results from the sedimentation and impaction methods may even differ many-fold (Blachno, 2009).

It may be stated that aerobic bacteria counts increased with the duration of the production process in most air sample collection sites. In the bulk products cooler, the bacterial counts on the three successive dates were $35 \mathrm{cfu} / \mathrm{m}^{3}, 125 \mathrm{cfu} / \mathrm{m}^{3}$ and $195 \mathrm{cfu} /$ $\mathrm{m}^{3}$. However, such a sequential dependence was not observed when the sedimentation method was applied. The highest yeast and mold counts using the impaction method were determined on date II, i.e., on a day with a high production rate. However, it should be stressed that the yeast and mold counts were high in the air samples collected on all tested dates, as well as in the measured locations in production facilities. For example, in a similar study by Kręgiel (2006), the highest mold count determined in the air of the production floor of a plant producing packing for the food industry was $1243 \mathrm{cfu} / \mathrm{m}^{3}$. That author reported a high correlation coefficient $(r=0.96)$ between the degree of fungal air contamination and microbial contamination of packages.

Table 1 - Aerobic bacteria and yeast and mold counts obtained by the sedimentation method, according to sampling site.

\begin{tabular}{|c|c|c|c|c|c|c|}
\hline \multirow{3}{*}{ Type of room } & \multicolumn{6}{|c|}{ Sedimentation method } \\
\hline & \multicolumn{3}{|c|}{$\begin{array}{c}\text { Aerobic bacteria } \\
\left(\mathrm{cfu} / \mathrm{m}^{3}\right)\end{array}$} & \multicolumn{3}{|c|}{$\begin{array}{l}\text { Yeast and molds } \\
\quad\left(\mathrm{cfu} / \mathrm{m}^{3}\right)\end{array}$} \\
\hline & Date I & Date II & Date III & Date I & Date II & Date III \\
\hline Bulk products cooler & 2129 & 74 & 55 & 1240 & 74 & 300 \\
\hline Outside tunnel IV & 185 & 1063 & 255 & 46 & 204 & 55 \\
\hline Inside tunnel IV & 3000 & 56 & 1233 & 1509 & 222 & 250 \\
\hline Exit of tunnel IV & 166 & 296 & 148 & 74 & 320 & 185 \\
\hline Packing hall I & 603 & 111 & 296 & 490 & 280 & 190 \\
\hline Production floor, in front of tunnels I and II & 278 & 74 & 19 & 120 & 74 & 18 \\
\hline
\end{tabular}

Explanatory note: for Dates I, II, III, average values of three replicates are given $(n=3)$ 
At present, Poland does not have sufficient legal regulations on microbial air quality requirements in food production. Moreover, there are no proposals for the classification of air quality in poultry processing plants (Górny \& Dutkiewicz, 2002). When applying the criterion specified by Krzysztofik (1992), which establishes $50 \mathrm{cfu} / \mathrm{m}^{3}$ as maximum yeast and mold count in the air of meat-processing, we may state that the count for this microbial group was considerably exceeded in the analyzed plant (Krzysztofik, 1992). In accordance with the observations reported by Kręgiel (2006), it seems justified to recommend simultaneous analyses of air contamination in production facilities and of product contamination, in order to establish individual values of selected parameters for the conditions in a given plant (Kręgiel, 2006).

The objective of collecting air samples at different locations of production facilities was to analyze air quality and to identify potential causes of high air contamination levels. The high aerobic bacteria counts, exceeding the allowable level of $500 \mathrm{cfu} / \mathrm{m}^{3}$, as determined in the air inside tunnel IV, in which 16 air-conditions are turned on simultaneously, indicates a significant effect of air-conditioning and cooling systems on the recorded results. Following a review of the documentation, the probable cause of the high level of air contamination in that location was found to be connected with an insufficient frequency of filter replacement in the air-conditioning and cooling devices. Other causes for the increase in the microbial counts in air include the course of the production process and its intensification during the work shift, resulting in changes in humidity and temperature, as well as (as observed during course of the analyses) inappropriate communication between employees and the relatively frequent incorrect behavior of employees, including, e.g., not wearing a face mask (Haagsma et al., 2012).

The fact that different air contamination levels were recorded using the sedimentation method indicates that, under the conditions in which the measurements were taken, it is difficult to obtain reliable and definite results. The sedimentation method is simple and easy to apply, but has many drawbacks, e.g., the plate may be colonized not only by microorganisms from the air column above the plate, but also by those transported by air convection currents, and it is impossible to determine precisely the volume of tested air (Kręgiel, 2006). The sampling points used in this study are also areas with an intensive air movement and, due to the operation of ventilators, fans and air-conditioners, the amounts of microorganisms colonizing the medium varied. This observation confirms the opinion that the sedimentation method should be selected to assess air contamination in locations with limited air movement (Cundith et al., 2002).

In this case, a much better solution was provided by the application of the impaction method, using a MAS-100 Eco air sampler, which allowed a more accurate assessment of the level of air contamination at any location (Kręgiel, 2006). Salustiano et al. (2003) mentioned that the impaction technique should be chosen since it can better recover airborne microorganisms, including pathogens. In addition of its simple operation and the reduced sample collection time, the primary advantage of the air sampler is the possibility to conduct a standardized evaluation of the regularly identical amount of air. As it was shown, the use of such a device also makes it possible to compensate for the effect of numerous external factors, particularly those connected with air movement. However, due to the considerable variability of the recorded results, it seems justified to perform the measurements according to a precise and specific sampling schedule, using a much greater number of replicates. An important element of air quality supervision in meat-production facilities should also include regular training of the employees, increasing their professional knowledge, and, in particular, eliminating behaviors and habits that pose risks to the hygiene and safety of the produced food.

\section{CONCLUSIONS}

In the investigations conducted under commercial scale production conditions, the air sampler used was shown to be suitable for measurements of air contamination levels in selected production facilities in a poultry processing plant. The device is easy to use and operate, and ready-to-use, commercially available media, specific for the investigated group of microorganisms, may be applied. The air sampler is small and handy, and fits perfectly into the HACCP concept.

The application of the impaction method and sampling of pre-programmed amount of air using an air sample allows to determine the level of microorganisms in a known volume of air and provides more reliable results in comparison with the sedimentation method, in which the amount of tested air cannot be precisely determined.

In light of the results collected during this study and considering poultry processing needs, the impaction sampler offers benefits in terms of convenience; 
however, care must be taken not to allow agar plates to remain in the sampler heads for too long, or the medium may dry out and deteriorate.

The analyses indicated a relatively high degree of microbial contamination of the air in the production facilities of the evaluated food production plant. Monitoring of air purity allows to immediately undertake corrective measures, such as improved supervision practices and replacement of filters in cooling and air-conditioning equipment, as well as training of employees.

Effective hygiene control, including air contamination, is vital to prevent the adverse human health and economic consequences of foodborne diseases and food spoilage.

\section{REFERENCES}

Battersby S. Procedures for pest control in the food industry. London: Chartered Institute of Environmental Health; 2009. p.1-56.

Blachno B. Waste containers as a source of microbiological air pollution. Environmental Protection and Natural Resources 2009;41:362-368.

Buchanan RL, Smith JL, Long W. Microbial risk assessment: dose-response relations and risk characterization. International Journal of Food Microbiology 2009;58:159-172.

Burrel R. Microbiological agents as health risks in indoor air. Envinronmental Health Perspectives 1991;95:29-34.

Collins $\mathrm{CH}$, Lyne PM, Grange JM. Microbiological methods. London: Butterwords; 1989.

Cundith CJ, Kerth CR, Jones WR, McCaskey TA, Kuhlers DL. Air-cleaning system effectiveness for control of airborne microbes in a meatprocessing plant. Journal of Food Science 2002;67(3):1170-1174.

EHEDG - European Hygienic Engineering \& Design Group. Guidelines on air handling in the food industry. Trends in Food Science \& Technology 2006;17:331-336.

Ellerbroek L. Airborne microflora in poultry slaughtering establishments. Food Microbiology 1997; 14:527-531.

Evers EG, Chardon JE. A swift quantitative microbiological risk assessment (sQMRA) tool. Food Control 2010;21:319-330.

Górny RL, Dutkiewicz J. Bacterial and fungal aerosols in indoor environment in Central and Eastern European countries. Annals of Agricultural and Environmental Medicine 2002;9:17-23.
Haagsma JA, Tariq L, Heederik DJ, Havelaar AH. Infectious disease risks associated with occupational exposure: a systematic review of the literature. Occupational and Environmental Medicine 2012:69:140146 .

Helm-Archer AA, Kerth CR, Jones WR, McCaskey TA, Conner D.E. Relationship between aerosolized microbial load and contamination of fully cooked then frozen meat products. Journal of Food Science 2004;69(1):13-16

Jain AK. Survey of bioaerosol in different indoor working environments in central India. Aerobiologia 2000;16:221-225.

Kaiser K, Wolski A. Control of air microbial quality. Refrigeration \& AirConditioning Engineering 2007;4:159-162.

Kang YI, Frank FJ. Biological aerosols: A review of airborne contamination and its measurement in dairy processing plants. Journal of Food Protection 1989;52:512-524.

Kręgiel D. The microbial contamination of a technological shop-floor air and the quality of packaging manufactured. Food. Science. Technology Quality 2006;1(46):52-58.

Krzysztofik B. Air microbiology. Warsawa: University of Technology; 1992.

Kalwasińska A, Burkowska A, Wilk I. Microbial air contamination in indoor environment of a university library. Annals of Agricultural and Environmental Medicine 2013;19(1):25-29.

Lues JFR, Theron MM, Venter P, Rasephei MHR. Microbial composition in bioaerosols of a high-throughput chicken-slaughtering facility. Poultry Science 2007;86:142-149.

Ogórek R, Pląskowska E. The mycological analysis of air in selected public rooms. Preliminary study. Medical Mycology 2011;18(1):24-29.

Salustiano VC, Andrade NJ, Brandão SCC, Azeredo RMC, Lima SAK. Microbiological air quality of processing areas in a dairy plant as evaluated by the sedimentation technique and a one-stage air sampler. Brazilian Journal of Microbiology 2003;34:255-259.

Srikanth P, Sudharsanam S, Steinberg R. Bio-aerosols in indoor environment: composition, health effects and analysis. Indian Journal of Medical Microbiology 2008;26:302-312.

Syne SM, Ramsubhag A, Adesiyum AA. Microbiological hazard analysis of ready-to-eat processed meats processed at a food plant in Trinidad, West Indies. Infection Ecology and Epidemiology 2013;3:20450.

Whyte P, Collins JD, McGill K, Monahan C, O'Mahony H. Distribution and prevalence of airborne microorganisms in three commercial poultry processing plants. Journal of Food Protection 2001;64(3):388-391.

Wiejak A. The assessment of air contamination with the mould fungi spores as an essential factor of mycological report. Building Research Institute 2011;3(159):3-12 